\title{
Influences of Annealing on the Electrical Properties of $\mathrm{Ba}_{0,5} \mathrm{Sr}_{0,5} \mathrm{TiO}_{3}$
}

\author{
Dwi Nugraheni Rositawati \\ Department of Physics Education, Faculty of Teacher Training and \\ Education, Sanata Dharma University, Yogyakarta, Indonesia \\ *Corresponding Author: wiwikfis@gmail.com
}

(Received 05-05-2019; Revised 14-05-2019; Accepted 14-05-2019)

\begin{abstract}
The research aims to investigate influences of annealing on the electrical properties of $\mathrm{Ba}_{0,5} \mathrm{Sr}_{0,5} \mathrm{TiO}_{3}$. $\mathrm{Ba}_{0,5} \mathrm{Sr}_{0,5} \mathrm{TiO}_{3}$ material which was annealed at $900^{\circ} \mathrm{C}$ for 1,2 and 4 hours has better mechanical properties. It needs investigation for its electrical contribution, namely the correlation between grain and grain boundaries to values of resistance and capacitance. The changing of electrical properties was controlled by grain, grain boundary and the area between the sample and contact. The electrical properties of $\mathrm{Ba}_{0,5} \mathrm{Sr}_{0,5} \mathrm{TiO}_{3}$ were investigated by impedance spectroscopy in the room temperature. This method is able to separate the electrical and dielectric properties of the grain, grain boundary and the area between contact with the sample. ZsimpWin software was used to find out the equivalent electrical circuit, the resistance and capacitance value. It was observed that with the increase in annealing time the small grains resistance, the grain boundaries resistance, and the large grain capacitance value also increases. The resistance values of small grains and large grains were smaller than the grain boundaries resistance. The value of capacitance-resistance of the small grains and large grains were obtained values that tend to be smaller.
\end{abstract}




\section{International Journal of Applied Sciences and Smart Technologies}

Volume 1, Issue 1, pages 23-32

ISSN 2655-8564

Keywords: $\mathrm{Ba}_{0,5} \mathrm{Sr}_{0,5} \mathrm{TiO}_{3}$, annealing, grain, grain boundary.

\section{Introduction}

The rapid development and advancement of technology were influenced by the development of material as its basic material. The development of the material certainly is inseparable from the development of discoveries of properties superior of a material as its basic material [1]. Solid materials have been conveniently grouped into three basic categories: metals, ceramics, and polymers, a scheme based primarily on chemical makeup and atomic structure. Most materials fall into one distinct grouping or another. In addition, there are the composites that are engineered combinations of two or more different materials. A brief explanation of these material classifications and representative characteristics is offered next. Another category is advanced materialsthose used in high-technology applications, such as semiconductors, biomaterials, smart materials, and nanoengineered materials [1].

Barium Titanate material $\left(\mathrm{BaTiO}_{3}\right)$ was originally discovered in 1941. This material was ferroelectric [2]. The continues research were carried out in line with the discovery of interesting properties on Barium Titanate $\left(\mathrm{BaTiO}_{3}\right)$ material, namely the discovery of various attractive properties including the material is very practical because of its very stable chemical and mechanical properties. It has ferroelectric properties [3]. The application of Barium Titanate material $\left(\mathrm{BaTiO}_{3}\right)$ includes the fields of thermal, electricity, electromechanics, and electro-optics, namely as multilayer capacitors (MLCs), PTC thermistors, electro-optical equipment, dynamic random access memories (DRAM) and tunable capacitors for microwave technology [3-5]. Barium Strontium Titanate which has the chemical formula $\mathrm{BaSrTiO}_{3}$ or better known as BST is one type of material in the ceramic group. BST is a ferroelectric material which belongs to the type of perovskite formed from Barium Titanate $\left(\mathrm{BaTiO}_{3}\right)$ doped with Strontium ( $\mathrm{Sr}$ ). Addition of Strontium to Barium Titanate is able to change the nature of Barium Titanate because the nature of a material can be changed by heat treatment and by the addition of other substances [1].

This research was intended for the application of $\mathrm{Ba}_{0,5} \mathrm{Sr}_{0,5} \mathrm{TiO}_{3}$ as a thermistor PTC. One of the characteristics of PTC is the resistance of material will rise significantly if 


\section{International Journal of Applied Sciences and Smart Technologies}

Volume 1, Issue 1, pages 23-32

ISSN 2655-8564

the temperature of material increased [6]. The influences temperature on the material change the size of the grain which will cause a shift in the Curie point - the transition point from ferroelectric to paraelectric in the material $\mathrm{Ba}_{0,5} \mathrm{Sr}_{0,5} \mathrm{TiO}_{3}$ and phase transition. It shows that changing in electrical properties and transport mechanisms at room temperature and low temperatures are controlled by grain and grain boundaries. The addition of $\mathrm{Sr}$ to $\mathrm{BaTiO}_{3}$ will reduce the Curie temperature to room temperature [5] therefore it is important to examine the electrical conductivity of $\mathrm{Ba}_{0,5} \mathrm{Sr}_{0,5} \mathrm{TiO}_{3}$ material at room temperature.

The stimulus of electrical properties such as electrical conductivity and dielectric constant is the electric field [1]. The method that was used in this study is Impedance Spectroscopy. Impedance spectroscopy is an analytical method that is popular in the research and development of material science. This method provides relatively simple electrical measurements and the results can be related to complex material variables: starting from mass transport, chemical reaction rate, corrosion, amorphous and polycrystalline dielectric behavior, microstructure and the influences of composition on the conductance of solids. The Impedance Spectroscopic Method could separate the electrical and dielectric properties of the grain, grain boundary and the area between contact with the sample. The measurement impedance parameters helps identify the physical process and determines the types of electrical parameters that represent the system [7]. It is important to have an equivalent model that can provide electrical properties. The electrical properties of the material are determined by a series combination between grain and grain boundaries, each of them is represented by a parallel RC element. It can be said that material electrical circuits are equivalent to a series of two parallel RC elements [8]. $\mathrm{Ba}_{0,5} \mathrm{Sr}_{0,5} \mathrm{TiO}_{3}$ material which was annealed at $900^{\circ} \mathrm{C}$ for 1,2 and 4 hours has better mechanical properties than $\mathrm{Ba}_{0,5} \mathrm{Sr}_{0,5} \mathrm{TiO}_{3}$ material which was sintered [9]. In order to obtain a complete understanding of $\mathrm{Ba}_{0,5} \mathrm{Sr}_{0,5} \mathrm{TiO}_{3}$ material properties, it is necessary to examine the electrical properties of $\mathrm{Ba}_{0,5} \mathrm{Sr}_{0,5} \mathrm{TiO}_{3}$ which was annealed $900^{\circ} \mathrm{C}$ for 1,2 and 4 hours. For this reason, it is necessary to examine the contribution of electricity, namely the correlation between grain and grain boundary to the value of resistance and capacitance. The research aims to investigate influences of annealing on the electrical properties of $\mathrm{Ba}_{0,5} \mathrm{Sr}_{0,5} \mathrm{TiO}_{3}$. 


\section{International Journal of Applied Sciences and Smart Technologies}

Volume 1, Issue 1, pages 23-32

ISSN 2655-8564

\section{Research Methodology}

The materials which were used in this study were $\mathrm{Ba}_{0,5} \mathrm{Sr}_{0,5} \mathrm{TiO}_{3}$ samples. It were obtained from the annealing temperature at $900^{\circ} \mathrm{C}$ for 1,2 and 4 hours using Ney Vulcan furnaces 3-550. The sample $\mathrm{Ba}_{0,5} \mathrm{Sr}_{0,5} \mathrm{TiO}_{3}$ are shaped like a piece that have a diameter of $10 \mathrm{~mm}, 2 \mathrm{~mm}$ thick and have a mass of $0.5 \mathrm{gr}$. Samples of $\mathrm{Ba}_{0,5} \mathrm{Sr}_{0,5} \mathrm{TiO}_{3}$ which had been washed were given contact from fiber wire. Sample preparation is done by heating samples that have been given silver glue at temperature of $120^{\circ} \mathrm{C}$ for 1 hour using Memmert 1534 Furnace. The heating function is to quicken the glue drying process and to further glue the contact wire to the sample.

The prepared sample is ready to measured the value of the RLC with the RCL meter which has been calibrated. Since the measurements with RCL meter were very sensitive, it were done in a stable sample state. The measuring values are the impedance and phase angle of each sample at a frequency of $50 \mathrm{~Hz}-1 \mathrm{MHz}$. The measurement starts from a high frequency of $1 \mathrm{MHz}$ to a low frequency of $50 \mathrm{~Hz}$ to maintain the stability of the reading of the impedance value.

Data of impedance and phase angles are used to determine the real part of impedance $\left(Z_{\text {real }}\right)$ and imaginary part of impedance $\left(Z_{\text {imaginary }}\right)$. The data are used as input data for processing data with ZsimpWin program to obtain the impedance spectrum in the Nyquist plot. The ZsimpWin software is used to obtain the equivalent electrical circuit according to the physical state of the sample. By providing input impedance data and selecting the desired electrical circuit, the software will automatically match the impedance curve. The equivalent circuit depends on the character of the measured sample. The value of each electrical component characterizes the electrical properties of the sample.

\section{Results and Discussions}

Variation of $\mathrm{Z}_{\text {real }} \mathrm{vs} \log$ frequency on samples annealed at $900^{\circ} \mathrm{C}$ for 1,2 and 4 hours is presented Figure 1 . The $\mathrm{Z}_{\text {real }}$ value on samples annealed at $900^{\circ} \mathrm{C}$ for 4 hours increase significantly compared to the samples annealed at $900^{\circ} \mathrm{C}$ for 1 hour and 2 hours. The 


\section{International Journal of Applied Sciences and Smart Technologies}

Volume 1, Issue 1, pages 23-32

ISSN 2655-8564

increasing in annealing time will increase the $\mathrm{Z}_{\text {real }}$ value. It shows decreasing in $\mathrm{AC}$ conductivity.

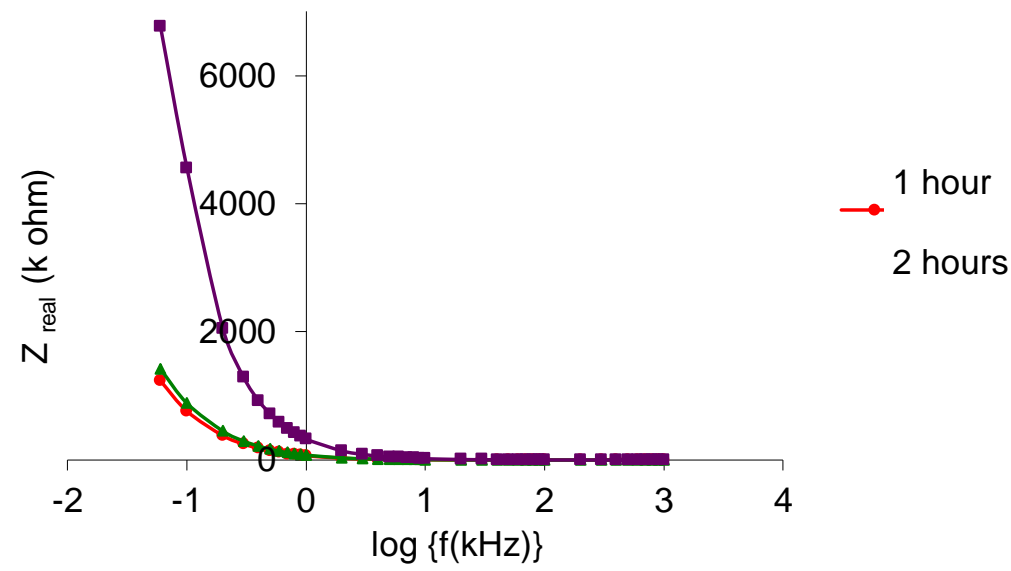

Figure 1. Graph of $Z_{\text {real }}$ vs $\log$ frequency

(annealed at $900^{\circ} \mathrm{C}$ for 1 hour, 2 hours and 4 hours)

Figure 1 also shows that the $Z_{\text {real }}$ value of the high-frequency $\log$ is much smaller than the low-frequency $\log$. It indicates that $\mathrm{Z}_{\text {real }}$ at high frequencies, grains contribute to electrical conduction, while at low frequencies the role is at the grain boundary. The changing in impedance spectrum occurs more often at low frequencies, namely at the grain boundary because it is a less stable area.

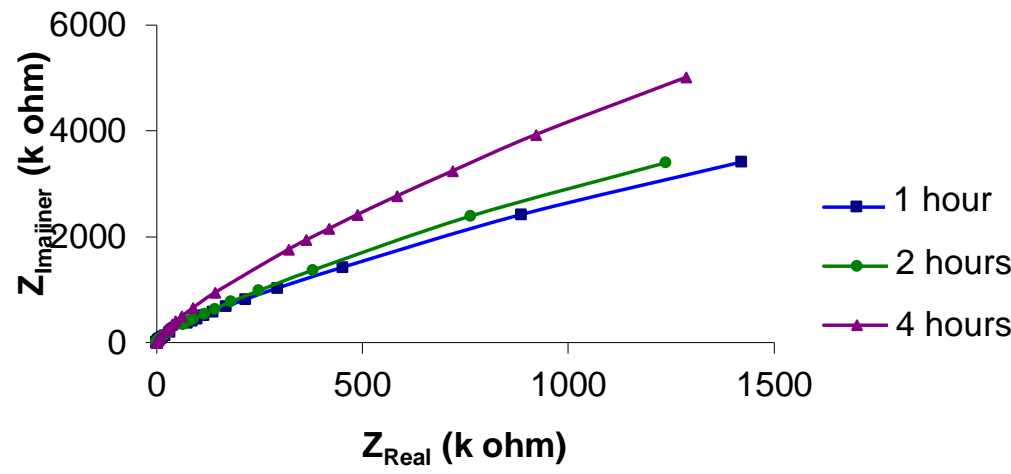

Figure 2. Comparison of Nyquist plots (annealed at $900^{\circ} \mathrm{C}$ for 1 hour, 2 hours and 4 hours) 


\section{International Journal of Applied Sciences and Smart Technologies}

Volume 1, Issue 1, pages 23-32

ISSN 2655-8564

Figure 2 shows comparison of Nyquist plots (annealed at $900^{\circ} \mathrm{C}$ for 1 hour, 2 hours and 4 hours). It shows that the increasing time of annealing causes the Impedance Spectrum curve to become larger and higher. It indicates the changing in the resistance and capacitance values in the sample.

The value of electrical elements can be obtained by modeling the electrical circuit from the Nyquist curve with fittings using the ZsimpWin program. After fitting in several electrical circuits, the most suitable electrical circuit obtained which is the model circuit in the sample is as shown in Figure 3.

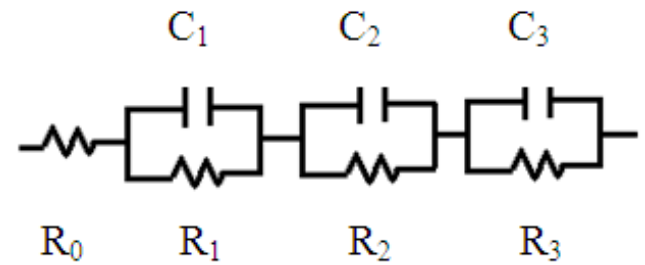

Figure 3. Equivalent electrical circuit; $R_{0}=$ interface resistance; $R_{1} \& C_{1}=$ resistance \& grain capacitance (small size); $\mathrm{R}_{2} \& \mathrm{C}_{2}=$ grain boundary resistance \& capacitance; $\mathrm{R}_{3} \& \mathrm{C}_{3}=$ grain resistance $\&$ capacitance (large size)

Comparison of measurement data with the results of fittings on samples annealed at $900^{\circ} \mathrm{C}$ for 1 hour, 2 hours and 4 hours are shown in Figure 4, Figure 5 and Figure $6 .$.

\section{Annealing $900^{\circ} \mathrm{C} 1$ jam}

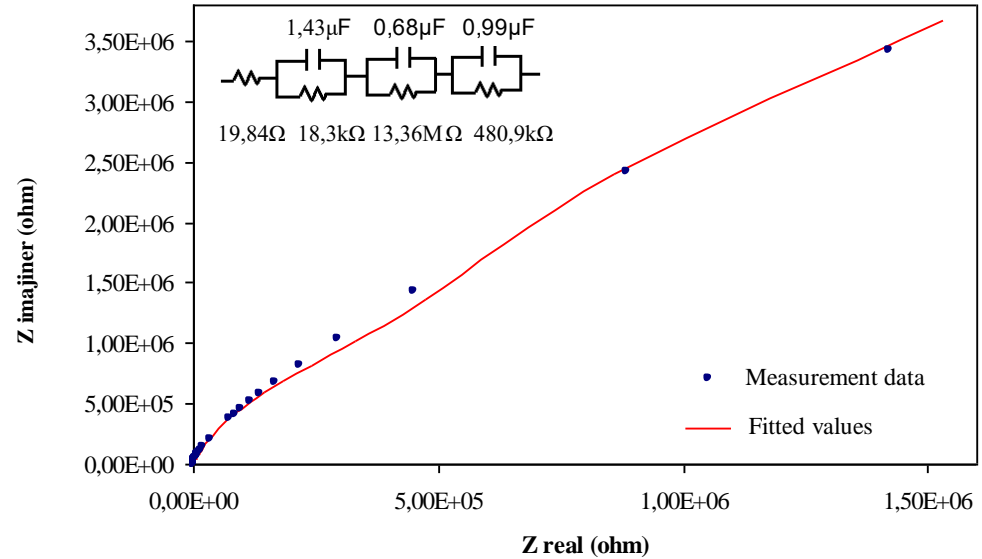

Figure 4. Comparison of measurement data $\&$ the results of fitting on samples annealed at $900^{\circ} \mathrm{C}$ for 1 hour 


\section{International Journal of Applied Sciences and Smart Technologies}

Volume 1, Issue 1, pages 23-32

ISSN 2655-8564

Annealing $900^{\circ} \mathrm{C} 2$ jam

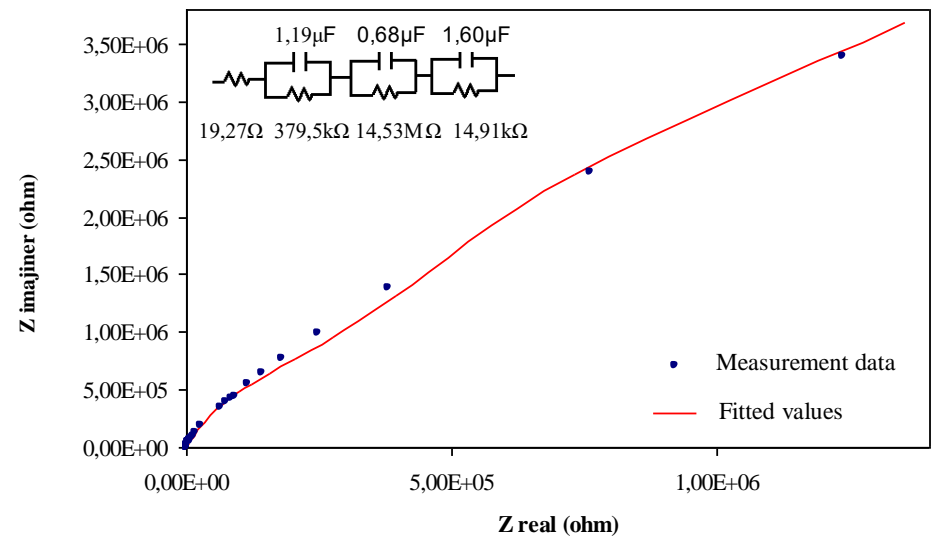

Figure 5. Comparison of measurement data \& the results of fitting on samples annealed at $900^{\circ} \mathrm{C}$ for 2 hours

Annealing $900^{\circ} \mathrm{C} 4 \mathrm{jam}$

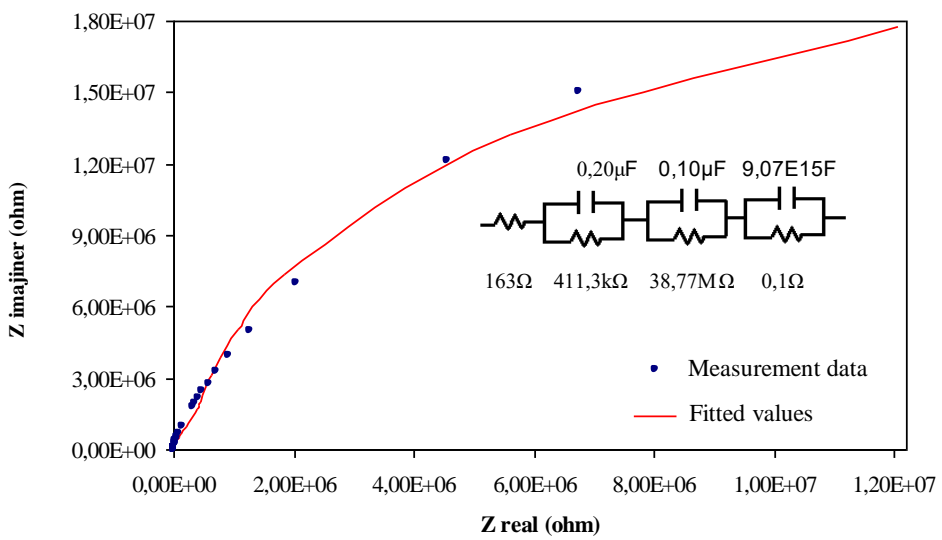

Figure 6. Comparison of measurement data $\&$ the results of fitting on samples annealed at $900^{\circ} \mathrm{C}$ for 4 hours 


\section{International Journal of Applied Sciences and Smart Technologies}

Volume 1, Issue 1, pages 23-32

ISSN 2655-8564

The resistance and capacitance values which were obtained from the results of fitting by ZsimpWin were summarized in Table 1.

Table 1. Value of resistance and capacitance

\begin{tabular}{cccc}
\hline Circuit & \multicolumn{3}{c}{ Annealed at $900^{\circ} \mathbf{C}$} \\
\cline { 2 - 4 } element & $\mathbf{1}$ hour & $\mathbf{2}$ hours & $\mathbf{4}$ hours \\
\hline $\mathrm{R}_{0}(\Omega)$ & 19,84 & 19,27 & 163 \\
$\mathrm{C}_{1}(\mu \mathrm{F})$ & 1,43 & 1,19 & 0,20 \\
$\mathrm{R}_{1}(\mathrm{k} \Omega)$ & 18,3 & 379,5 & 411,3 \\
$\mathrm{C}_{2}(\mu \mathrm{F})$ & 0,68 & 0,68 & 0,10 \\
$\mathrm{R}_{2}(\mathrm{M} \Omega)$ & 13,36 & 14,53 & 38,77 \\
$\mathrm{C}_{3}(\mathrm{~F})$ & $0,99 E-6$ & $1,60 E-6$ & $9,07 E 15$ \\
$\mathrm{R}_{3}(\mathrm{k} \Omega)$ & 480,9 & 14,91 & $0,1 E-3$ \\
\hline
\end{tabular}

Table 1 shows that the resistance values of small grains and large grains were smaller than the grain boundaries resistance. Grains were more stable than grain boundaries so that the resistance value were smaller. It was observed that with the increase in annealing time the small grains resistance, the grain boundaries resistance, and the large grain capacitance value also increases. The annealing process can be used to reduce the thermal stress that is known from cracks which are found to be smaller according to the increase in annealing time. Annealing is also able to improve microstructure which is to produce smaller, homogeneous grains and not to find porosity [9]. The contact area between one item and another becomes more and more so that it produces resistance and the capacitance gets bigger. The value of capacitance-resistance of the small grains and large grains were obtained values that tend to be smaller, this is probably due to the distribution of grains that have not been homogeneous in the sample layer [9].

\section{Conclusions}

Influences of annealing on the electrical properties of $\mathrm{Ba}_{0,5} \mathrm{Sr}_{0,5} \mathrm{TiO}_{3}$ can be written as follows:

a. It was observed that with the increase in annealing time the small grains resistance, the grain boundaries resistance, and the large grain capacitance value also increases. 


\section{International Journal of Applied Sciences and Smart Technologies}

Volume 1, Issue 1, pages 23-32

ISSN 2655-8564

b. The resistance values of small grains and large grains were smaller than the grain boundaries resistance.

c. The value of capacitance-resistance of the small grains and large grains were obtained values that tend to be smaller.

\section{References}

[1] W. D. Callister, "Material science and engineering-third edition", John Willey and Sons, New York, 1994.

[2] W. Heywang and H. Thomann, "Tailoring of piezoelectric ceramics," Annual Review of Materials Science, 14, 27-47, 1984.

[3] H. Lin and Wang, "Structure and dielectric properties of perovskite-barium titanate $\left(\mathrm{BaTiO}_{3}\right)$, , San Jose State University, 2002.

[4] H. Y. Tian, W. G. Luo, A. L. Ding, J. Choi, C. Lee, and K. S. No, "Influences of annealing temperature on the optical and structural properties of $(\mathrm{Ba}, \mathrm{Sr}) \mathrm{TiO}_{3}$ thin films derived from sol-gel technique," Thin Solid Films, 200-205, 2002.

[5] T. Hungría, M. Algueró, A. B. Hungría, and A. Castro, "Dense, fine-grained Ba1${ }_{x} \mathrm{Sr}_{\mathrm{x}} \mathrm{TiO}_{3}$ ceramics prepared by the combination of mechanosynthesized nanopowders and spark plasma sintering," Chemistry of Materials, 6205-6212, 2005.

[6] W. Cao, H. H. Cudney, and R. Waser, "Smart materials and structures," Proceedings of the National Academy of Sciences of the United States of America, 8330-8331, July 1999.

[7] S. Sen, R. N. P. Choudhary, and P. Pramanik, "Impedance spectroscopy of $\mathrm{Ba}_{-\mathrm{x}} \mathrm{Sr}_{\mathrm{x}} \mathrm{Sn}_{0.15} \mathrm{Ti}_{0.85} \mathrm{O}_{3}$ ceramics," British Ceramic Transactions, 250-256, 2004.

[8] K. Prabakar, S. K. Narayandass, and D. Mangalaraj, "Impedance and electric modulus analysis of $\mathrm{Cd}_{0.6} \mathrm{Zn}_{0.4}$ Te thin films," Crystal Research and Technology, 37 (10), 1094-1103, 2002.

[9] D. N. Rositawati, "Studi pengaruh annealing terhadap keramik barium strontium titanate," Prosiding Seminar Nasional Sains dan Pendidikan Sains VI, 210-215, Juli 2011. 
International Journal of Applied Sciences and Smart Technologies

Volume 1, Issue 1, pages 23-32

ISSN 2655-8564

This page intentionally left blank 